\title{
Micromotion-induced peri-prosthetic fluid flow around a cementless femoral stem
}

\author{
Valérie Malfroy Camine, Alexandre Terrier and Dominique P. Pioletti \\ Laboratory of Biomechanical Orthopedics, Ecole Polytechnique Fédérale de Lausanne, Lausanne, Switzerland
}

\begin{abstract}
Micromotion-induced interstitial fluid flow at the bone-implant interface has been proposed to play an important role in aseptic loosening of cementless implants. High fluid velocities are thought to promote aseptic loosening through activation of osteoclasts, shear stress induced control of mesenchymal stem cells differentiation, or transport of molecules. In this study, our objectives were to characterize and quantify micromotion-induced fluid flow around a cementless femoral stem using finite element modeling. With a 2D model of the bone-implant interface and full-factorial design, we first evaluated the relative influence of material properties, and bone-implant micromotion and gap on fluid velocity. Transverse sections around a femoral stem were built from computed tomography images, while boundary conditions were obtained from experimental measurements on the same femur. In a second step, a 3D model was built from the same data-set to estimate the shear stress experienced by cells hosted in the peri-implant tissues. The full-factorial design analysis showed that local micromotion had the most influence on peak fluid velocity at the interface. Remarkable variations in fluid velocity were observed in the macrostructures at the surface of the implant in the $2 \mathrm{D}$ transverse sections of the stem. The $3 \mathrm{D}$ model predicted peak fluid velocities extending up to $2.2 \mathrm{~mm} / \mathrm{s}$ in the granulation tissue and to $3.9 \mathrm{~mm} / \mathrm{s}$ in the trabecular bone. Peak shear stresses on the cells hosted in these tissues ranged from 0.1 to $12.5 \mathrm{~Pa}$. These results offer insight into mechanical stimuli encountered at the bone-implant interface.
\end{abstract}

\section{ARTICLE HISTORY}

Received 17 January 2017

Accepted 15 February 2017

\section{KEYWORDS}

Cementless total hip arthroplasty; micromotion; interstitial fluid flow; femoral stem

\section{Introduction}

During the past two decades, the number of cementless hip replacements has increased significantly (Wyatt et al. 2014). With the rising number of young patients undergoing hip replacement, improving the long-term success of cementless femoral stems has become a crucial issue in the field of total hip replacement. Aseptic loosening is the main cause for revision of cementless hip stems, accounting for $54 \%$ of all causes for revision (Wyatt et al. 2014). It is characterized by the formation of a fibrous tissue at the bone-implant interface and areas of osteolysis around the implant.

Aseptic loosening is a complex process, usually due to a combination of mechanical and biological factors, but is largely related to the initial phases of peri-implant healing (Kärrholm et al. 1994; Mjöberg 1994). Shortly after implantation, a soft and porous tissue saturated with interstitial fluid fills the gap between the bone and the implant. This granulation tissue hosts mesenchymal stem cells (MSCs) that have the ability to differentiate into osteoblasts leading to bone formation. The fate of MSCs is directly linked to mechanical and biochemical stimuli in their environment.

Among the factors that are known to play a role in implant loosening, primary stability of the implant is critical. Primary stability corresponds to the initial mechanical fixation of the implant, and is characterized by relative bone-implant micromotion at the interface. Excessive bone-implant micromotion indicates a poor implant primary stability and has been shown to promote the formation of interfacial fibrous tissue, leading to aseptic loosening (Engh et al. 1992; Søballe et al. 1992).

Fluid flow has also been shown to play an important role in promoting aseptic loosening. High fluid velocities (Fahlgren et al. 2010) and pressures (Van der Vis et al. 1998) have been reported to cause osteolysis, independently from the presence of wear particles. Fluid shear stress is also known to play a role in controlling MSCs osteoblastic differentiation (Kreke et al. 2005; Arnsdorf et al. 2009, 2009; Yourek et al. 2010).

CONTACT Dominique P.Pioletti dominique.pioletti@epfl.ch

(4) Supplemental data for this article can be accessed at http:/dx.doi.org/10.1080/10255842.2017.1296954

(C) 2017 Informa UK Limited, trading as Taylor \& Francis Group 
It has been suggested that micromotion and fluid flow at the bone-implant interface could be intimately related (Prendergast et al. 1997). Implant micromotion deforms the surrounding bone and granulation tissue, hereby pumping interstitial fluid and generating fluid flow. Micromotion-induced fluid flow would thus have the potential to affect the outcome of peri-implant healing, through stimulation of the MSCs hosted in the bone and the granulation tissue, activation of the osteoclasts, or transport of morphogens, nutrients, oxygen or wear particles.

For this reason, there has been a growing interest to quantify micromotion-induced fluid flow around implants, in order to help study its effects on periimplant healing and osseointegration. Various studies in the recent years tried to characterize micromotioninduced fluid flow (Conroy et al. 2006; Alidousti et al. 2011; Mann \& Miller 2014). Most of these studies considered simplified bone and implant geometries, unidirectional homogeneous micromotion, or were limited to $2 \mathrm{D}$ fluid velocities. However, the heterogeneous local micromechanical environment is known to play an important role in peri-implant healing (Simmons et al. 2001, 2006). Moreover, the material properties of the granulation tissue are ill-defined. Different values for Young's modulus, porosity and permeability have been proposed - depending on where and when the tissue was collected - and the commonly used value for Poisson's ratio (0.167) is based on a value measured in cartilage (Jurvelin et al. 1997; Isaksson et al. 2009). The nature of the interstitial fluid is also unclear, and its viscosity remains unknown.

The aim of this study is to characterize and quantify micromotion-induced fluid flow at the bone-implant interface of a cementless femoral stem, using finite element (FE) modeling with accurate geometries and boundary conditions. The study is divided into two specific objectives: (i) to determine the relative influence of material properties of granulation tissue, micromotion, and geometry on fluid velocities at the bone-implant interface, using design of experiments (DOE) and an idealized 2D model of the bone-implant interface, and (ii) to quantify micromotion-induced 3D fluid velocities around the whole bone-implant interface of a cementless femoral stem, and the resulting shear stress on cells hosted in peri-implant tissues.

\section{Materials and methods}

\section{D parametric model of the bone-implant interface}

A 2D poroelastic finite element (FE) model of the bone-implant interface was created and combined with a design of experiments (DOE) approach, to explore the effects of implant micromotion, gap size, and material properties of the granulation tissue and interstitial fluid on peak fluid velocity in peri-implant tissues.

\section{FE Model's geometry}

The model was composed of three concentric rings: the most central one represented the granulation tissue, which was surrounded by a ring of trabecular bone and a ring of cortical bone (Figure 1). The most central boundary represented an implant with a diameter of $1 \mathrm{~cm}$. The implant was considered completely rigid and impermeable compared to the surrounding tissues. The cortical and trabecular thicknesses were both $5 \mathrm{~mm}$. The gap between the implant and trabecular bone was considered as fully filled with granulation tissue.

\section{Material properties, boundary, and initial conditions}

Granulation tissue, trabecular and cortical bones were modeled as poroelastic and saturated with interstitial fluid (Table 1). The poroelastic properties of trabecular and cortical bone were obtained from the literature. Some studies have focused on characterizing the poroelastic properties of the fibrous tissue that forms ultimately at the bone-implant interface of loosened implants, and we assumed that granulation tissue had similar properties. The Biot-Willis effective stress coefficient, which relates the volume of fluid expelled or sucked into a porous material element with the volumetric change of the same element, was unknown for trabecular bone and granulation tissue. Because of inhibition of pore compression, a stiff porous matrix has a Biot-Willis coefficient close to its porosity, and a soft porous matrix has a Biot-Willis coefficient close to 1 (Podichetty \& Madihally 2014). Therefore, we assumed Biot-Willis coefficients of 0.8 for trabecular bone and 1 for granulation tissue. The properties of the interstitial fluid were those of water.

The external boundary of the cortical bone was fully constrained. Micromotion of the implant was imposed by a sinusoidal displacement in the $x$-direction, at a

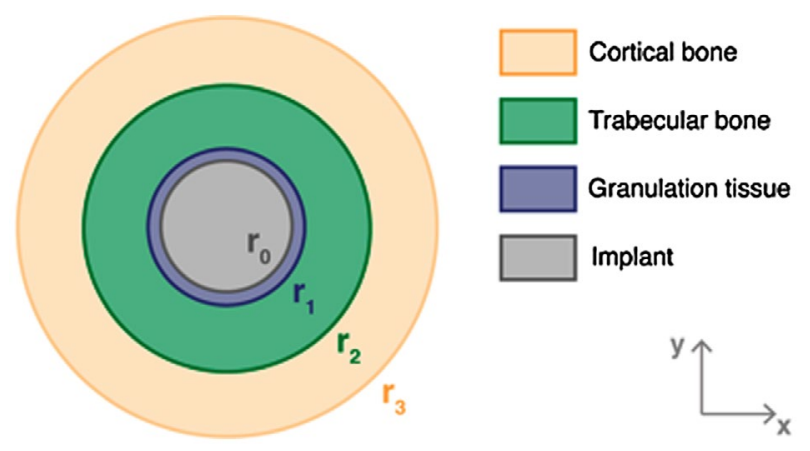

Figure 1. Geometry of the idealized model $-r_{i}$ designates boundaries of the model. 
frequency of $1 \mathrm{~Hz}$. We introduced a phase shift of $-\frac{\pi}{2}$ to enable a gradual initial ramping of micromotion and help convergence. The implant boundary was impermeable to fluid and the external boundary of cortical bone was open boundary to fluid flow. For the initial conditions, the system was considered to be at rest, with a fluid pore pressure at $1 \mathrm{~atm}$ in all tissues.

\section{Finite element analysis}

The model was meshed with solid triangular elements (Table S1) and implemented in COMSOL (COMSOL Multiphysics $^{\oplus}$ 5.2a, www.comsol.com, COMSOL AB, Stockholm, Sweden) using the poroelasticity interface. The time-dependent partial differential equations were solved with a fully-coupled approach using the NewtonRaphson iteration method and a direct MUMPS solver. Time steps sizes were determined automatically using backward differentiation formula. Outcome measures of the model were peak fluid velocity in the trabecular bone and in the granulation tissue.

\section{Design of experiments approach}

A full factorial design with two levels was chosen to study the relative impact of boundary conditions and material properties on peak fluid velocity in the trabecular bone and in the granulation tissue. The factors included in the design were bone-implant gap size, implant micromotion, granulation tissue's Young's modulus, Poisson's ratio, permeability and porosity, and interstitial fluid's viscosity.

The choice of local gap size and micromotion levels was made so as to span the variety of results measured experimentally in a previous study (Malfroy Camine et al. 2016).
To study the effects of variations in material properties of the granulation tissue, the levels of each material property were chosen to span a range of proposed values in the literature. Finally, water and bone marrow were chosen to span the possible viscosity values for the interstitial fluid.

With two levels and seven factors, the design resulted in $128\left(2^{7}\right)$ conditions (Table 2).

The full factorial design was generated and analyzed in Minitab (Minitab 17 Statistical Software, www.minitab. com, Minitab, Inc., State College, PA, USA) using ANOVA. Only main effects and 2-way interactions were considered.

\section{D fluid flow around a cementless femoral stem}

A 3D poroelastic FE model of the same femur where micromotion were measured experimentally was built, based on the geometry obtained from CT data. The field of micromotion measured experimentally was used as boundary condition.

\section{FE Model's geometry}

Two CT-scans were performed after broaching of the bone cavity and after implantation respectively. The geometry of the bone-implant interface was reconstructed from the post-broaching CT-scan. Cortical and trabecular bone were segmented manually in the Amira software (Amira v6.0.1, FEI, Hillsboro, OR,USA) and the bone surfaces were reconstructed in Geomagic (Geomagic Studio 2014, 3D Systems, Rock Hill, SC, USA). The bone surfaces were aligned to the post-implantation CT-scan and a simplified version of the implant surface, without macrostructures, was subtracted in Solidworks (Solidworks 2015,

Table 1. Sensitivity study: full-factorial design factors and levels.

\begin{tabular}{|c|c|c|c|}
\hline Factors & Low level & High level & References \\
\hline Gap size & $0.5 \mathrm{~mm}$ & $5 \mathrm{~mm}$ & (Malfroy Camine et al. 2016) \\
\hline Micromotion & $5 \mu \mathrm{m}$ & $250 \mu \mathrm{m}$ & (Malfroy Camine et al. 2016) \\
\hline Young's modulus of granulation tissue & $0.5 \mathrm{MPa}$ & $1.5 \mathrm{MPa}$ & (Leong \& Morgan 2008)*, (Kraaij et al. 2014; Moerman et al. 2016) \\
\hline Poisson's ratio of granulation tissue & 0.1 & 0.3 & (Jurvelin et al. 1997) $)^{* * *},\left(\right.$ Kiviranta et al. 2006) ${ }^{* * *}$ \\
\hline Porosity of granulation tissue & 0.7 & 0.9 & (Diamond 1999)† \\
\hline Permeability of granulation tissue & $1 e^{-14} \mathrm{~m}^{2}$ & $5 \mathrm{e}^{-14} \mathrm{~m}^{2}$ & (Diamond 1999)†, (Fahlgren et al. 2012)* \\
\hline Interstitial fluid's viscosity & 0.001 Pa.s & 0.1 Pa.s & (Gurkan \& Akkus 2008)†† \\
\hline
\end{tabular}

${ }^{*}$ Measured in granulation tissue; ${ }^{* *}$ Measured in the bone-implant interface tissue of loosened implants;

***Measured in cartilage; †Measured in blood clots

††Measured in bone marrow.

Table 2. Poroelastic material properties used in the model.

\begin{tabular}{|c|c|c|c|c|c|c|c|}
\hline Material & Density & $\begin{array}{l}\text { Young's } \\
\text { modulus }\end{array}$ & Poisson's ratio & Porosity & Permeability & $\begin{array}{l}\text { Biot-Willis } \\
\text { coefficient }\end{array}$ & Viscosity \\
\hline Cortical bone & $\begin{array}{l}1875 \mathrm{~kg} / \mathrm{m}^{3} \text { (Ashman } \\
\text { et al. } 1984 \text { ) }\end{array}$ & $\begin{array}{l}\text { 15.75 GPa (Smit } \\
\text { et al. 2002) }\end{array}$ & $\begin{array}{l}0.325 \text { (Smit et al. } \\
\text { 2002) }\end{array}$ & $\begin{array}{l}0.05 \text { (Smit et al. } \\
\text { 2002) }\end{array}$ & $\begin{array}{l}1.5 \mathrm{e}^{-20} \mathrm{~m}^{2} \text { (John- } \\
\text { son et al. 1982) }\end{array}$ & $\begin{array}{l}0.14 \text { (Cowin } \\
1999)\end{array}$ & \\
\hline Trabecular bone & $\begin{array}{l}1875 \mathrm{~kg} / \mathrm{m}^{3} \text { (Ashman } \\
\text { et al. 1984) }\end{array}$ & $\begin{array}{l}1 \text { GPa (Kohles \& } \\
\text { Roberts 2002) }\end{array}$ & $\begin{array}{l}0.25 \text { (Sebaa et al. } \\
2006 \text { ) }\end{array}$ & $\begin{array}{l}0.8 \text { (Kohles \& } \\
\text { Roberts 2002) }\end{array}$ & $\begin{array}{l}4.7 \mathrm{e}^{-10} \mathrm{~m}^{2} \text { (Kohles } \\
\text { \& Roberts 2002) }\end{array}$ & 0.8 & \\
\hline $\begin{array}{l}\text { Granulation } \\
\text { tissue }\end{array}$ & $\begin{array}{c}1100 \text { kg/m³ (Nahirn- } \\
\text { yak et al. 2006) }\end{array}$ & $\begin{array}{l}0.99 \mathrm{MPa} \text { (Leong } \\
\text { \& Morgan 2008) }\end{array}$ & $\begin{array}{l}0.167 \text { (Isaksson et } \\
\text { al. 2009) }\end{array}$ & $\begin{array}{l}0.8 \text { (Diamond } \\
\text { 1999) }\end{array}$ & $\begin{array}{l}3 \mathrm{e}^{-14} \mathrm{~m}^{2} \text { (Fahlgren } \\
\text { et al. 2012) }\end{array}$ & 0.95 & \\
\hline Interstitial fluid & $1000 \mathrm{~kg} / \mathrm{m}^{3}$ & & & & & & $1 \mathrm{e}^{-3}$ Pa.s \\
\hline
\end{tabular}




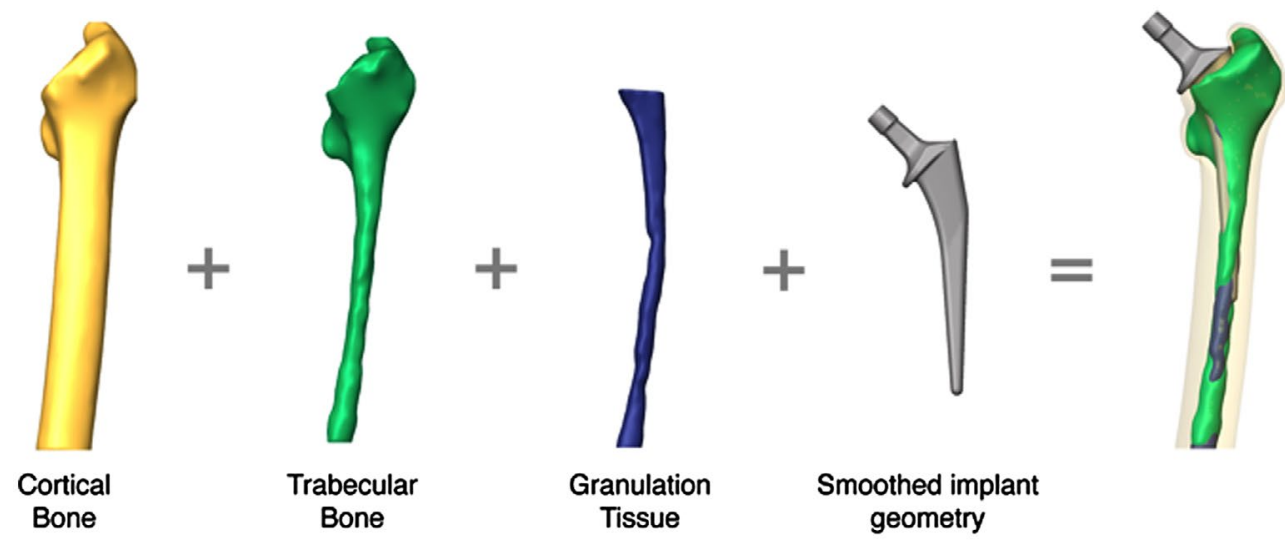

Figure 2. Assembly of geometry for the 3D model - The model is built from the cortical bone (yellow), trabecular bone (green), granulation tissue (red) and simplified implant surfaces (blue).

Solidworks Corp., Dassault Systemes, Waltham, MA, USA) (Figure 2).

\section{Material properties, boundary, and initial conditions}

The material properties (Table 1), were identical to those of the $2 \mathrm{D}$ model. The initial and boundary conditions were similar, except for the amplitude and direction of micromotion, which were defined according to the interpolation function of 3D bone-implant micromotion around the stem, measured locally using a micro-CT based experimental technique (Figure S1) (Malfroy Camine et al. 2016).

\section{Finite element analysis}

The model was meshed with tetrahedral elements (Table S1) and solved in COMSOL, similar to what was described above. Outcome measures of the model included average and peak fluid velocity in each tissue, and the peak shear stress on cells located in trabecular bone and granulation tissue. The peak shear stress on cells was estimated assuming spherical cells embedded in a porous matrix (Wang \& Tarbell 2000):

$$
\tau=\frac{3}{\pi} \frac{\mu \nu}{\sqrt{\kappa}}
$$

where $\tau$ is the peak shear stress on cells, $\mu$ is the interstitial fluid viscosity, $v$ is the peak fluid's velocity in the tissue and $\kappa$ is the permeability.

\section{Results}

\section{D parametric model of the bone-implant interface}

Peak fluid velocity in the tissues of the bone-implant interface reached two maxima over one micromotion cycle due to inflow and outflow, at approximately 25 and $75 \%$ of the
Table 3. ANOVA for the full factorial design. Degrees of freedom (DOF) and percentages of the total sum of squares (\%TSS) are listed. Only significant effects are displayed.

\begin{tabular}{lrrr}
\hline Source & DOF & \%TSS (\%) & $p$-value \\
\hline Linear & 7 & 89.5 & $<0.001$ \\
$\quad$ Gap size & 1 & 2.6 & $<0.001$ \\
Micromotion & 1 & 84.2 & $<0.001$ \\
$\quad$ Granulation tissue's permeability & 1 & 0.1 & 0.003 \\
$\quad$ Interstitial fluid's viscosity & 1 & 2.6 & $<0.001$ \\
2-Way Interactions & 21 & 7.9 & $<0.001$ \\
Gap size $\times$ Micromotion & 1 & 2.6 & $<0.001$ \\
Gap size $\times$ Interstitial fluid's viscosity & 1 & 0.9 & $<0.001$ \\
$\quad$ Micromotion $\times$ Granulation tissue's & 1 & 0.9 & 0.004 \\
permeability & 1 & 2.6 & $<0.001$ \\
$\quad$ Micromotion $\times$ Interstitial fluid's & 1 & & 0.017 \\
viscosity & & 0.9 & \\
$\quad$ Granulation tissue's permeability $\times$ & 1 & & \\
Interstitial fluid's viscosity & & & \\
Residuals & 99 & & \\
\hline
\end{tabular}

load cycle. The maximal fluid velocity was encountered in the trabecular bone. Peak fluid velocity ranged from 5 to $1277 \mu \mathrm{m} / \mathrm{s}$, depending on the levels of parameters included in the full factorial design.

The analysis of the full factorial design of experiments showed that gap size, micromotion, tissue's permeability and interstitial fluid viscosity had a significant $(p<0.05)$ effect on peak fluid velocity at the bone-implant interface (Table 3). Micromotion was the parameter that influenced the most the peak fluid velocity, with higher micromotion resulting in higher fluid velocity. The mean fluid velocity for all low micromotion conditions was $18 \mu \mathrm{m} / \mathrm{s}$, versus $1062 \mu \mathrm{m} / \mathrm{s}$ for all high micromotion conditions. Low gap size resulted in significantly higher fluid velocity and low fluid viscosity induced lower peak fluid velocity, but they both contributed to less than 3\% of the total sum of squares. Additionally, several 2-way interactions were also significant, including the interaction between gap size and micromotion that contributed to $2.6 \%$ of the total sum of squares. 

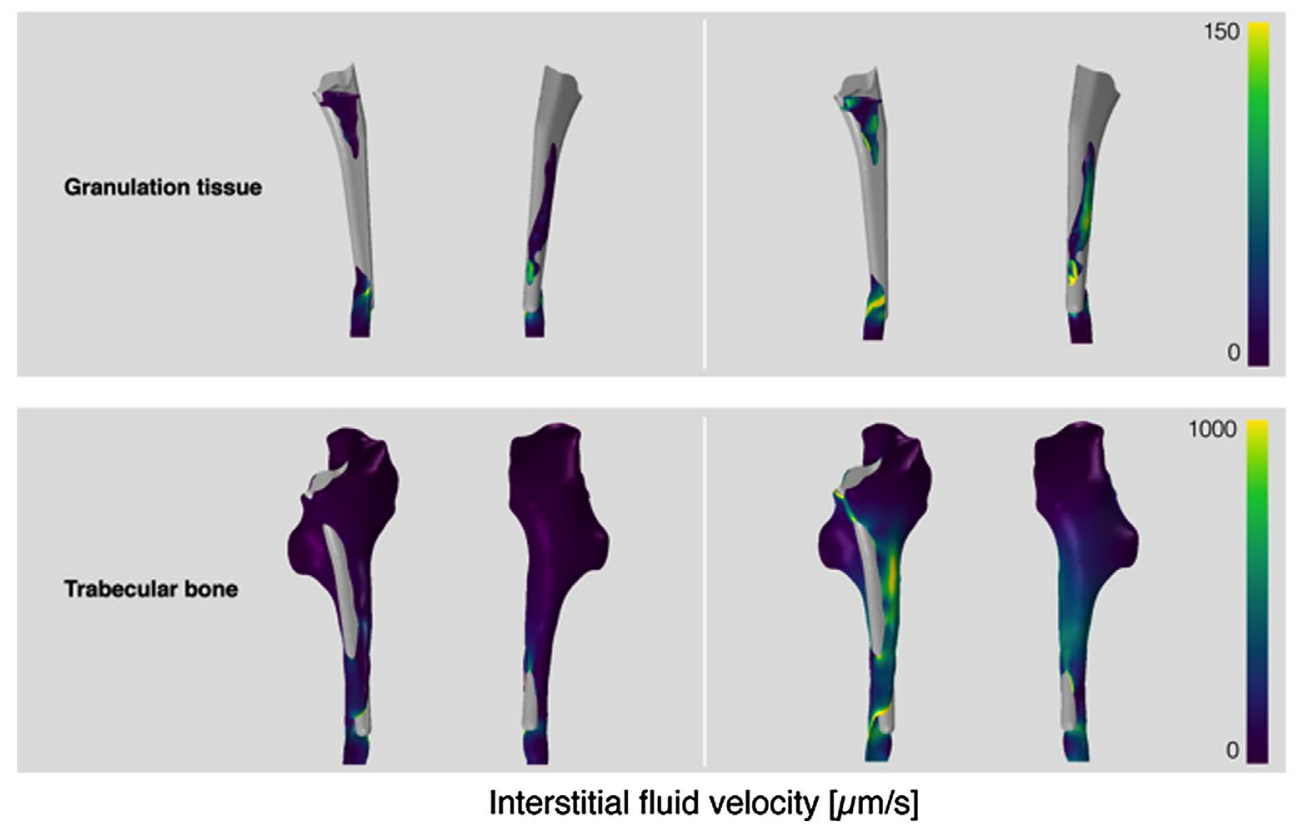

Figure 3. Distribution of micromotion-induced interstitial fluid velocities in the granulation tissue and trabecular bone around a simplified cementless femoral stem (gray) in compression and torsion at $t=0.25 \mathrm{~s}$.

\section{D fluid flow around a simplified cementless femoral stem}

The average fluid velocity in the granulation tissue was $9 \mu \mathrm{m} / \mathrm{s}$ in compression and $15 \mu \mathrm{m} / \mathrm{s}$ in torsion. In the trabecular bone, the average fluid velocity was much higher, with $21 \mu \mathrm{m} / \mathrm{s}$ in compression and $128 \mu \mathrm{m} / \mathrm{s}$ in torsion.

The peak fluid velocity in the granulation tissue was maximal close to the distal end of the stem for both loading cases, reaching $412 \mu \mathrm{m} / \mathrm{s}$ in compression and $2273 \mu \mathrm{m} / \mathrm{s}$ in torsion (Figure 3). In the trabecular bone, peak fluid velocities occurred distally in compression with $1804 \mu \mathrm{m} / \mathrm{s}$ and on the middle and distal diaphysis in torsion with a maximum at $3913 \mu \mathrm{m} / \mathrm{s}$. The interstitial fluid velocities in cortical bone were much lower than in other tissues, and the highest fluid velocities recorded (up to $5.5 \mu \mathrm{m} / \mathrm{s}$ ) were at the distal end of the stem for both loading cases. The most important component of the 3D fluid velocity was in the longitudinal direction.

Peak shear stress in granulation tissue was 2.3 and 12.5 Pa for compression and torsion respectively. In trabecular bone, shear stress on cells reached 0.1 and $0.2 \mathrm{~Pa}$ for compression and torsion.

\section{Discussion}

Micromotion-induced fluid flow at the bone-implant interface is believed to play an important role in the initial phases of peri-implant healing, through stimulation of cells hosted in the surrounding tissues. However, quantification of micromotion-induced fluid velocities around accurate geometries and based on the local mechanical environment of the prosthesis was missing. In this study, our objective was to use FE modeling to characterize and quantify micromotion-induced fluid velocity at the bone-implant interface of a cementless femoral stem using accurate geometries and experimentally measured local micromotion. Using design of experiments and an idealized 2D model of the bone-implant interface, we observed that micromotion was the most influential parameter on peak fluid velocity at the interface. The geometry of the interface, represented by the gap size, as well as the interactions between gap size and micromotion, played also a significant role, underlining the need for accurate geometries and local micromotion measurements when estimating micromotion-induced fluid flow. Then, using a 3D model of the bone-implant interface, we obtained a range of fluid velocities extending up to $2200 \mu \mathrm{m} / \mathrm{s}$ in the granulation tissue and to $3900 \mu \mathrm{m} / \mathrm{s}$ in the trabecular bone for a torsional loading case.

The main strength of the model developed as part of this work is that it captures the wide range of combined gap and micromotion conditions around the stem, thanks to full-field measurements. The exact sequence of events that links micromotion-induced fluid flow to aseptic loosening remains unknown. Nevertheless, the model presented in this study could be appropriate to test some of the hypotheses around the mechanisms behind aseptic loosening. 
Previous researches already reported the important effect of surface geometries (Simmons et al. 2001, 2006) and micromotion (Engh et al. 1992; Søballe et al. 1992) on peri-implant healing. Our findings are consistent with these studies, as we found that gap size and micromotion influenced peak fluid velocities to a greater extent than material properties. Other models that estimated micromotion-induced fluid flow at the bone-implant interface reported fluid velocities similar to what we estimated. The micromotion-induced peak fluid velocity at the bone-cement interface of retrieved transverse sections of cemented femoral stems varied from 270 to $15700 \mu \mathrm{m} / \mathrm{s}$ (Mann \& Miller 2014). In another model of capsular pressure and micromotion-induced fluid flow around a cementless femoral stem, fluid velocities extending up to $3000 \mu \mathrm{m} / \mathrm{s}$ were observed (Alidousti et al. 2011). In a magnetic resonance imaging study, micromotion-induced fluid velocity in the gap around a canine bone implant model reached $14000 \mu \mathrm{m} / \mathrm{s}$ (Conroy et al. 2006). Fahlgren et al. (2010) observed osteolysis for fluid velocities over $20000 \mu \mathrm{m} / \mathrm{s}$, while our range of values was in the order of hundreds of $\mu \mathrm{m} / \mathrm{s}$. Finally, flow chamber experiments showed that fluid shear stress in the order of 0.4 to $2.2 \mathrm{~Pa}$ could induce the osteogenic differentiation of MSCs, which relates well with the range of shear stresses in granulation tissue that we estimated.

The present study has several limitations, and the most important one is that results for only one specimen are reported. Future works will require several samples to confirm the results obtained with this model and account for patient's variability. The geometries were reconstructed from a CT-scan with a resolution of $0.5 \mathrm{~mm}$, meaning that gaps smaller than the resolution were not modeled. Furthermore, the implant macrostructures were not included in the 3D model to reduce mesh size and computation time. The material properties of granulation tissue are not well characterized, and the measured poroelastic properties for trabecular and cortical bone span a wide range of values. Additionally, the material properties of the interface are likely to be anisotropic and evolve as healing progresses. Nevertheless, we evaluated the sensitivity of peak fluid velocities to the material properties of granulation tissue using design of experiments techniques, and found that despite some properties like the permeability of the tissue or the viscosity of the fluid influenced significantly the results, their role was minimal compared to the effects of gap size or micromotion. We also assumed that the mechanical behavior of the granulation tissue was linear elastic. However, small gaps and high micromotion could easily result in large strains, for which the linear elastic representation would no longer be valid. The hyperelastic properties of the interfacial fibrous tissue around loosened cementless stem were recently characterized
(Kraaij et al. 2014; Moerman et al. 2016). Further studies should evaluate the repercussions of the hyperelastic modeling of interfacial tissue on micromotion-induced fluid flow predictions. Fluid-flow at the interface results from both implant micromotion and bone deformation following implant loading, however, our measurements of implant micromotion reports the relative displacement between the implant and bone and does not integrate bone strains. It is thus possible that our range of fluid velocities is slightly underestimated. Finally, Darcy's law is only valid for low Reynolds number $\mathrm{Re}<10$ (Hassanizadeh \& Gray 1987). Using a characteristic pore length of $1 \mu \mathrm{m}$ for granulation tissue and $1 \mathrm{~mm}$ for trabecular bone, we estimated Reynolds numbers of 0.001 and 1 for each tissue respectively. Therefore, in this study, Darcy's flow was a reasonable assumption. However, higher fluid velocities arising with higher implant micromotion could lead to non-Darcy's flows.

This study provided a first estimation of local micromotion-induced fluid flow around a cementless femoral stem in the initial stages of peri-implant healing. Though the mechanisms that link fluid flow at the initial bone-implant interface and peri-implant healing remain insufficiently understood, much research in the recent years focused on the influence of fluid flow on bone and mesenchymal stem cells. The range of fluid velocities and shear stresses estimated in this study is of great interest to relate with results from mechanobiology experiments with mechanical stimuli encountered at the bone-implant interface. Furthermore, micromotion-induced fluid flow has been proposed to disturb the transport of morphogens in the peri-implant tissues, hereby affecting the osteogenic differentiation of mesenchymal stem cells (Gortchacow et al. 2013). In the future, a model of morphogens transport in the granulation tissue could be combined with the model developed in this study, to test this hypothesis.

\section{Acknowledgements}

The authors thank Dr. Hannes Rüdiger for performing the surgery on the cadaveric femur, DePuy Synthes (DePuy Synthes Joint Reconstruction, Warsaw, IN, USA) for donating the implants, instruments and CAD files, and Alejandro Dominguez and the Centre Universitaire Romand de Médecine Légale (CURML) for the CT-scans of the femurs.

\section{Disclosure statement}

No potential conflict of interest was reported by the authors.

\section{Funding}

This work was supported by the Swiss National Science Foundation [grant number \#141152]; the SwissLife Jubiläumstiftung. 


\section{References}

Alidousti H, Taylor M, Bressloff NW. 2011. Do capsular pressure and implant motion interact to cause high pressure in the periprosthetic bone in total hip replacement? J Biomech Eng. 133:121001. doi:10.1115/1.4005455

Arnsdorf EJ, Tummala P, Jacobs CR. 2009. Non-canonical Wnt signaling and $\mathrm{N}$-cadherin related $\beta$-catenin signaling play a role in mechanically induced osteogenic cell fate. PLoS One. 4:e5388. Bergmann A, editor.

Arnsdorf EJ, Tummala P, Kwon RY, Jacobs CR. 2009. Mechanically induced osteogenic differentiation - the role of RhoA, ROCKII and cytoskeletal dynamics. J Cell Sci. 122:546-553.

Ashman RB, Cowin SC, Van Buskirk WC, Rice JC. 1984. A continuous wave technique for the measurement of the elastic properties of cortical bone. J Biomech. 17:349-361.

Conroy MJ, Pedrono A, Bechtold JE, Søballe K, Ambard D, Swider P. 2006. High-resolution magnetic resonance flow imaging in a model of porous bone-implant interface. Magn Reson Imaging. 24:657-661.

Cowin SC. 1999. Bone poroelasticity. J Biomech. 32:217-238.

Diamond SL. 1999. Engineering design of optimal strategies for blood clot dissolution. Annu Rev Biomed Eng. 1:427-461.

Engh CA, O'Connor D, Jasty M, McGovern TF, Bobyn JD, Harris WH. 1992. Quantification of implant micromotion, strain shielding, and bone resorption with porous-coated anatomic medullary locking femoral prostheses. Clin Orthop Relat Res. 285:13-29.

Fahlgren A, Bostrom MPG, Yang X, Johansson L, Edlund U, Agholme F, Aspenberg P. 2010. Fluid pressure and flow as a cause of bone resorption. Acta Orthop. 81:508-516.

Fahlgren A, Johansson L, Edlund U. 2012. Direct ex vivo measurement of the fluid permeability of loose scar tissue. Acta Bioeng Biomech. 14:47-51.

Gortchacow M, Terrier A, Pioletti DP. 2013. A flow sensing model for mesenchymal stromal cells using morphogen dynamics. Biophys J. 104:2132-2136.

Gurkan UA, Akkus O. 2008. The mechanical environment of bone marrow: a review. Ann Biomed Eng. 36:1978-1991.

Hassanizadeh SM, Gray WG. 1987. High velocity flow in porous media. Transp Porous Med. 2:521-531.

Isaksson H, van Donkelaar CC, Ito K. 2009. Sensitivity of tissue differentiation and bone healing predictions to tissue properties. J Biomech. 42:555-564.

Johnson MW, Chakkalakal DA, Harper RA, Katz JL, Rouhana SW. 1982. Fluid flow in bone in vitro. J Biomech. 15:881-885.

Jurvelin JS, Buschmann MD, Hunziker EB. 1997. Optical and mechanical determination of poisson's ratio of adult bovine humeral articular cartilage. J Biomech. 30:235-241.

Kärrholm J, Borssén B, Löwenhielm G, Snorrason F. 1994. Does early micromotion of femoral stem prostheses matter? 4-7-year stereoradiographic follow-up of 84 cemented prostheses. J Bone Joint Surg Br. 76:912-917.

Kiviranta P, Rieppo J, Korhonen RK, Julkunen P, Töyräs J, Jurvelin JS. 2006. Collagen network primarily controls Poisson's ratio of bovine articular cartilage in compression. J Orthop Res. 24:690-699.

Kohles SS, Roberts JB. 2002. Linear poroelastic cancellous bone anisotropy: trabecular solid elastic and fluid transport properties. J Biomech Eng. 124:521-526.

Kraaij G, Zadpoor AA, Tuijthof GJM, Dankelman J, Nelissen RGHH, Valstar ER. 2014. Mechanical properties of human bone-implant interface tissue in aseptically loose hip implants. J Mech Behav Biomed Mater. 38:59-68.
Kreke MR, Huckle WR, Goldstein AS. 2005. Fluid flow stimulates expression of osteopontin and bone sialoprotein by bone marrow stromal cells in a temporally dependent manner. Bone. 36:1047-1055.

Leong PL, Morgan EF. 2008. Measurement of fracture callus material properties via nanoindentation. Acta Biomater. 4:1569-1575.

Malfroy Camine V, Rüdiger H, Pioletti DP, Terrier A. 2016. Full-field measurement of micromotion around a cementless femoral stem using micro-CT imaging and radiopaque markers. J Biomech. 49:4002-4008.

Mann KA, Miller MA. 2014. Fluid-structure interactions in micro-interlocked regions of the cement-bone interface. Comp Methods Biomech Biomed Eng. 17:1809-1820.

Mjöberg B. 1994. Theories of wear and loosening in hip prostheses: wear-induced loosening vs loosening-induced wear-a review. Acta Orthop. 65:361-371.

Moerman A, Zadpoor AA, Oostlander A, Schoeman M, Rahnamay Moshtagh P, Pouran B, Valstar E. 2016. Structural and mechanical characterisation of the peri-prosthetic tissue surrounding loosened hip prostheses. An explorative study. J Mech Behav Biomed Mater. 62:456-467.

Nahirnyak VM, Yoon SW, Holland CK. 2006. Acoustomechanical and thermal properties of clotted blood. J Acoust Soc Am. 119:3766-3772.

Podichetty JT, Madihally SV. 2014. Modeling of porous scaffold deformation induced by medium perfusion. J Biomed Mater Res Part B Appl Biomater. 102:737-748.

Prendergast PJ, Huiskes R, Søballe K. 1997. Biophysical stimuli on cells during tissue differentiation at implant interfaces. J Biomech. 30:539-548.

Sebaa N, Fellah ZEA, Fellah M, Ogam E, Wirgin A, Mitri FG, Depollier C, Lauriks W. 2006. Ultrasonic characterization of human cancellous bone using the Biot theory: inverse problem. J Acoust Soc Am. 120:1816-1824.

Simmons CA, Meguid SA, Pilliar RM. 2001. Mechanical regulation of localized and appositional bone formation around bone-interfacing implants. J Biomed Mater Res. 55:63-71.

Simmons CA, Meguid SA, Pilliar RM. 2006. Differences in osseointegration rate due to implant surface geometry can be explained by local tissue strains. J Orthop Res. 19: 187-194.

Smit TH, Huyghe JM, Cowin SC. 2002. Estimation of the poroelastic parameters of cortical bone. J Biomech. 35: 829-835.

Søballe K, Hansen ES, B Rasmussen H, Jørgensen PH, Bünger C. 1992. Tissue ingrowth into titanium and hydroxyapatitecoated implants during stable and unstable mechanical conditions. J Orthop Res. 10:285-299.

Van der Vis HM, Aspenberg P, Marti RK, Tigchelaar W, Van Noorden CJF. 1998. Fluid pressure causes bone resorption in a rabbit model of prosthetic loosening. Clin Orthop Relat Res. 350:201-208.

Wang S, Tarbell JM. 2000. Effect of fluid flow on smooth muscle cells in a 3-dimensional collagen gel model. Arterioscler Thromb Vasc Biol. 20:2220-2225.

Wyatt M, Hooper G, Frampton C, Rothwell A. 2014. Survival outcomes of cemented compared to uncemented stems in primary total hip replacement. WJO. 5:591-596.

Yourek G, McCormick SM, Mao JJ, Reilly GC. 2010. Shear stress induces osteogenic differentiation of human mesenchymal stem cells. Regen Med. 5:713-724. 